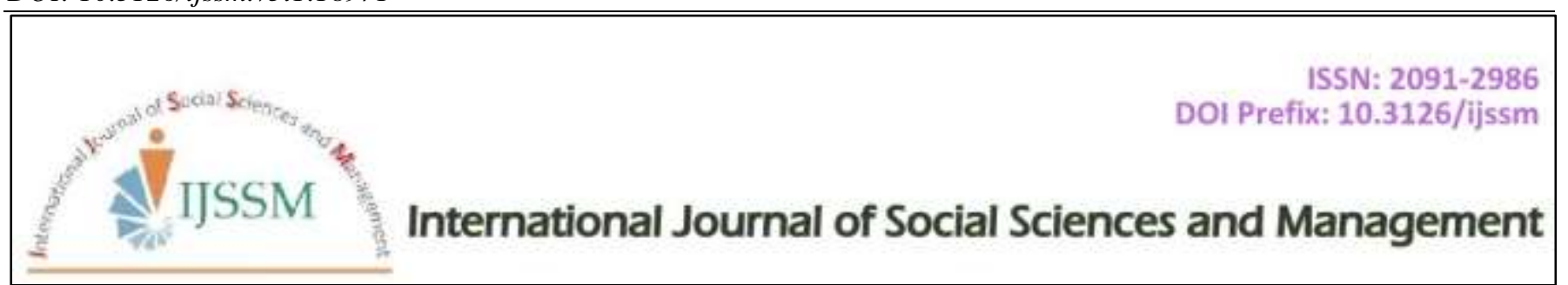

Research Article

\title{
Facebook Utilization and Arab Spring Movement: A Study among Yemeni Youth
}

\author{
Adnan Abdulrahman Naef Farhan ${ }^{1 *}$ and P.A. $\operatorname{Varghese}^{1}$ \\ ${ }^{1}$ Department of Journalism and Mass Communication, Kuvempu University, JnanaShayadri, Shankaraghatta, India.
}

\begin{abstract}
The Arab Spring is a popular term used to describe the revolutionary movement of demonstrations and protests, and civil wars in the Arab world that began on December 18, 2010 in Tunisia and spread in the whole Arab countries. Tunisia and Egypt became the center of this revolution, and then it moved to include Libya, Yemen, Bahrain, Syria, Algeria, Iraq, Jordan, Kuwait, Morocco, Sudan, Mauritania, Oman, Saudi Arabia, Djibouti, Western Sahara and Palestine. Yemeni youth's revolution movement began to change the system through mobilization of people and social action. This paper focuses on the importance of Facebook in the revolution and how the Yemeni youth used Facebook to attract more supporters and keep the spirit up. The present paper reports the impact of Facebook in nurturing political revolution in Yemen analyzing the data achieved by survey method.
\end{abstract}

Keywords: Facebook; Yemeni youth; social media

\section{Introduction}

The word media once referred only to print media, photography, advertising, cinema, radio and television, and folk media. However, with ever-increasing science and technological changes, a sea change occurred in the approach to media, their production, distribution and access. A revolution in the information and communication technology (ICT) has changed the media environment. For instance, earlier news channels were constructed and determined by their output mechanism but with the advent of internet or services related to ICT, it is not only the output and speed, but also the production process and formats (Knight, 2013). Thus, new media is characterized by the enormous changes in media production, distribution and access, with the digital, interactive, virtual, networked, and simulated technologies.

NCT enabled entire media content converted to digital format. Data in the form of text, images and sound are processed and stored as numbers and retrieved, copied as and when required, preserved in hard disk, memory drives and projected or broadcast in variety of ways.

Interactivity of new media provides a faster and powerful feedback system. To make new media interactive a unique coding language -- hypertext mark-up language (html) -has been developed. The main feature of using hypertext is hyperlinks that allow user to navigate, enter or exit through

\section{Cite this article as:}

A.A.N. Farhan and P.A. Varghese (2018) Int. J. Soc. Sc. Manage. Vol. 5, Issue-1: 5-9. DOI: 10.3126/ijssm.v5i1.18971

$1 *$ Corresponding author

Adnan Abdulrahman Naef Farhan,

Department of Journalism and Mass Communication, Kuvempu University, JnanaShayadri, Shankaraghatta, India

Email: adnanalomari1@gmail.com; Mob: 8951080883

Peer reviewed under authority of IJSSM

(C) 2018 International Journal of Social Sciences and Management

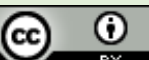

This is an open access article \& it is licensed under a Creative Commons Attribution 4.0 International License (https://creativecommons.org/licenses/by/4.0/)

Full text of this paper can be downloaded online at www.ijssm.org/ \&http://nepjol.info/index.php/IJSSM/issue/archive 
any document easily and swiftly (Hassouna, 2014). Further, new media provides virtual multi-sensory experience to people, though in reality they do not experience them, they feel that they had undergone the experience.

Social media help individuals and groups to share and communicate with each other through a web based platform. Users generate online content, distribute and consume it in an interactive platform. Yasemin Gülbahar as cited by Kietzmann et al. (2011) defines social media as "interactive web platforms via which individuals and communities share, co-create, discuss, and modify user-generated content”. Thus, social media are tools of communication and collaboration through the exchange of text, images, video, live streaming, and presentation.

\section{Social Media}

Social media help individuals and groups to share and communicate with each other through a web based platform. Users generate online content, distribute and consume it in an interactive platform. Yasemin Gülbahar as cited by Kietzmann et al. (2011) defines social media as "interactive web platforms via which individuals and communities share, co-create, discuss, and modify usergenerated content". Thus, social media are tools of communication and collaboration through the exchange of text, images, video, live streaming, and presentation.

\section{New Media and Social Movements}

Lindsay Ems (2014) pointed out that recent protests in Middle East, northern Africa, and the events like Occupy Wall Street movement are the by-products of modern social structures and technologies that channelized small street protests in well-organized social movements. They concluded that new communication tools result into a sociotechnical rallies. Sorour and Lal (2014) propounded that both in developed and developing societies, the social movements like anti-globalisation demonstrations in the West, mass protests at Tahrir Square in Cairo and Taksim Square in Istanbul, demonstrations against sexual harassment in Delhi and the Shahbag Square uprising in Dhaka were fuelled by substantial utilization of social media.

Lagos et al. (2013) observed that digital technologies provide a vital aid for individuals political expressions because of cost economy, user friendliness and enormous social network reach. Thus, importance of social media in organizing and sustaining the social movement is inevitable. Marom (2013) in his study focused on spatial politics proposed that there is relationship among physical public space and mainstream and social media. This relationship has provided a huge scope for street protests and mass rallies in Tel Aviv. Hence it can be asserted that social media amplifies social movements. Odine (2013) in the study entitled "Role of Social Media in the Empowerment of Arab Women" revealed that utilization of social media has empowered Arab women against the social and political discrimination. Social media helped them to bypass the media censorship.

Social media has given Arab women new hope to overcome their issues regarding education, health and employment. Kara Giannopoulos (2012) mentioned that social media was the main cause behind the Arab spring in Egypt and the green movement in Iran. Internet was considered as important power that helped the protesters to be connected and organize their revolution and the socio-political movement, however, propaganda created on internet was not optimally utilized sustain the modern political insurgencies. Chris Atton (2003) elucidates the role of Indymedia- the Internet-based network of Independent Media Centers (IMCs) against the World Trade Organization. This network provided the opportunity to various anti-capitalism groups to communicate, cooperate, collate and mobilize. The study describes the significance of organization, socio-politics and its news culture in galvanizing social movements.

Anthony et al. (2012) decisively measured cases across Africa of variegated employment of old (i.e. radio, newspaper, television) and new media platforms (Facebook, Twitter, mobile telephone text messaging) by using four social movements as reference during a period of 35 years. Estimations emphasize citizen empowerment and multiplier capabilities of new media but establish the value of contextual factors that minimize hyperbolic assumptions about the contribution of new media to the formation and progression of social movements. Their survey assessment observed that penetration of new ICTs into society with direct reference to their use in social movements had new forms of media superior than the traditional forms.

Ramesh Srinivasan (2014) argued that both liberals and conservatives in Egypt used in three ways to impact the political power. These include building and expanding the basis of heterogeneous and diverse networks of supporters, assembling bridges between older and newer media platforms, subverting their competition through misinformation.

Steinert-Threlkeld et al. (2015) contented that was the major factor in correlating large-scale decentralized protests that have opened new horizons for balance of power between the citizens and the state. They suggested that even weak ties can also facilitate mobilization by divulging individuals to information about participation from outside of their local, strong-tie social network, allowing those who are on the periphery of the protest. Thus, social media provides people platform for learning and coordination

More than half of the users in the Arab world use social media to connect with people primarily and for getting news, while getting information, watching videos, listening 
to music and sharing photos are the second most important reason to use them. Chats are the most common activity among Arab users, followed by blogs read by other users.

Over a decade, social media has shown increasing relevance to the daily lives of people and interaction between governments and their citizens. In 2009 social media It has grown in use in the Arab world after, the year sparking protests against governments in the Middle East, starting with Iran, and then in some Arab countries, in what is now known as the Arab Spring (www.arabsocialmediareport.com)

\section{The Arab Spring}

The Arab Spring is a popular term used to describe a revolutionary wave of demonstrations and protests (both non-violent and violent), riots, and civil wars in the Arab world that began on December 18, 2010 in Tunisia and spread to the completely Arab peninsula. Tunisia and Egypt became the hub of this revolution.

Tunisian revolution famously known as the 'Jasmine Revolution' started with series of street protests that began on December 18, 2010, the day after the self-immolation of Mohammed Bouazizi in Sidi Bouzidthat finally resulted in the ouster of longtime president Zine El Abidine Ben Ali in January 2011. The demonstrations were fueled by high unemployment, food inflation, cancerous corruption, absence of freedom of speech and miserable living conditions (Ryan, 2011).

Popularly known as 'January 25 Revolution', the Egyptian Revolution of 2011 instigated on Jan 25, 2011 swelled almost the entire Egypt. Millions of protesters marched towards the famous Tahrir square that included Islamic, liberal, anti-capitalist, nationalist and feminist elements to overthrow of Egyptian President Hosni Mubarak. The revolution was the result of legal and political issues that include police brutality, state-of-emergency laws, lack of free elections and freedom of speech, cancerous growth of corruption and economic crisis including high unemployment, food-price inflation and low wages (CNN Wire staff, 2011).

The events in these countries have cascading impact on other Middle East countries that include Libya, Yemen, Bahrain, Syria, Algeria, Iraq, Jordan, Kuwait, Morocco, Sudan, Mauritania, Oman, Saudi Arabia, Djibouti, Western Sahara and Palestine.

\section{Literature Review: Social Media and People Action}

Anthony et al (2012) studied cases across Africa of employment of old (i.e. radio, newspaper, television) and new media platforms (Facebook, Twitter, mobile telephone text messaging) by using four social movements as reference during a period of 35 years. Results emphasize citizen empowerment and multiplier capabilities of new media but establish the value of contextual factors that minimize hyperbolic assumptions about the contribution of new media to the formation and progression of social movements. Their study observed that ICTs in social movements had greater impact than the traditional forms.

Osrecki (2014) described the dialectical interrelation between media technology and democratic changes, and propounded that the new media technology only cemented the way to organization and exchange of information during 'Arab Spring', but was not its cause.

Tim Markham (2014) in his study pointed out that generative, self-organizing properties of protest cultures, that are mobilized with the aid of social media try to evade both authoritarian political structures and academic discourse, leading to new political subjectivities or 'imaginaries'. This power in protest cultures and social media enables affective political projection, but overlooks politics in its institutional and formal forms.

Christensen (2013) viewed diverse range of circulation of Arab music videos and public discourse; Lebanese bloggers and mediated public spheres; transnational television audiences and ontological security; social media, television talk shows, and political change in Egypt; youth-generated Arab media and cultural politics; and the Arab Spring as an ephemeral communicative space.

Kirat (2013) opined that new media can mobilize crowds and masses to rally and protest i.e. a social perspective to movements; however, they fail to implement democracy.Social media is unremittingly changing the creativity, social convergence and community relationship patterns of the people leading to new political and socioeconomic prospects of these countries.

\section{Objective and Methodology of the Study}

The objective of the present study was to assess how the Arab Spring activists value Facebookas a tool for their movement.

A structured questionnaire has been developed pre-tested and administered to the randomly selected 60 respondents from the Arab spring activists from Yemen. Data was gathered from 13 respondents over the phone and others through a research assistant in Yemen. The questions ranged from the patterns of accessing and utilizing Facebook to their perceptions and practices of using the social media for their movement.

\section{Results and Discussion}

All the respondents were active Facebook users. The study found that majority of the Arab spring activists (78.3\%) were using the Facebook for more than 3 years (Table 1). 
Table 1: Familiarity with Facebook

\begin{tabular}{|l|l|l|}
\hline Facebook Usage & No of Users & Percent \\
\hline 1 year & 2 & $2.75 \%$ \\
\hline 2 years & 11 & $18.3 \%$ \\
\hline 3 years \& above & 47 & $78.3 \%$ \\
\hline Total & 60 & $100 \%$ \\
\hline
\end{tabular}

Facebook related activity among the Arab Spring activists was very high. While 29 activists $(48.3 \%)$ spent more than one hour daily with Facebook, 25 of them (41.7\%) interacted with it more than half an hour, and only six of them spent below half an hour with this social media (Table 2).

Table 2: Time spent with Facebook

\begin{tabular}{|l|l|l|}
\hline Facebook Usage & No of Users & Percent \\
\hline $0-30$ minutes & 6 & 10.0 \\
\hline $30-60$ minutes & 25 & 41.7 \\
\hline More than 1 hr & 29 & 48.3 \\
\hline Total & 60 & $100 \%$ \\
\hline
\end{tabular}

All the Activists were accessing Facebook on their mobile phone as they travelled or in their personal computer at home. As printed newspapers and television are very difficult to access due to heavy war and distribution / broadcast hazards, most of the respondents' usually access news through internet based platforms (Fig. 1).

Arab spring activists utilizes Facebook to gather news from Yemen, and friends living outside Yemen, and to keep in touch with them. All the respondents were either very active in Yemen $(70 \%)$ or outside Yemen $(30 \%)$ (Table 3).

Table 3: Arab Spring Participation Level

\begin{tabular}{|l|l|l|}
\hline Participation Level & Frequency & Percent \\
\hline Very active in Yemen & 42 & $70 \%$ \\
\hline Very active outside Yemen & 18 & $30 \%$ \\
\hline Total & 60 & $100 \%$ \\
\hline
\end{tabular}

Table 4 shows that $60 \%$ activists associated with Arab spring perceive that Facebook has substantial impact on the whole movement in Yemen whereas $40 \%$ suggested that television channels had contributed greater impact for the movement.

Table 4: Impact of various media on Arab Spring

\begin{tabular}{|l|l|l|}
\hline Media & Frequency & Percent \\
\hline Facebook & 36 & $60 \%$ \\
\hline TV Channels & 24 & $40 \%$ \\
\hline Total & 60 & $100 \%$ \\
\hline
\end{tabular}

As Table 5 shows that all the respondents were actively sharing, commenting and searching for additional information after receiving a Facebook post. None of them just read and forget. Most of them (88.3\%) shared all interesting FB posts with the friends; however, if the post was related to Arab Spring, they would post to all friends in the movement. Further seven of them (11.7\%) would even call other friends to gather news and information in detail.

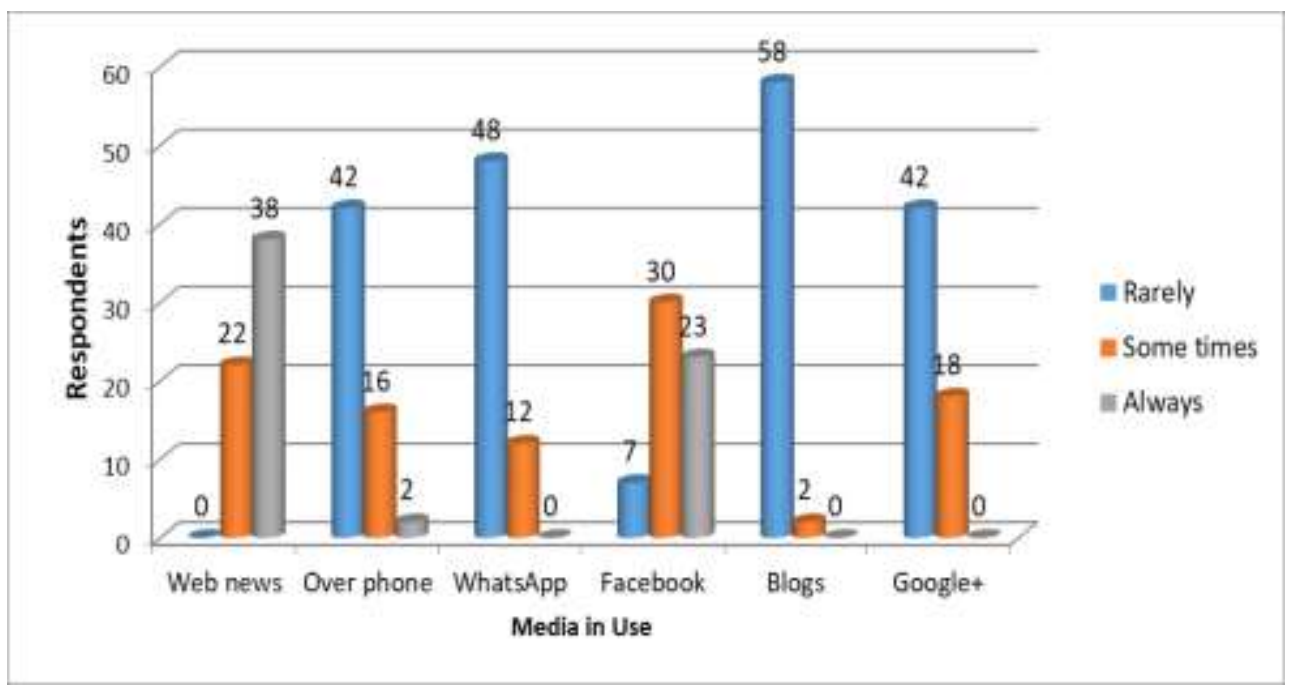

Fig. 1: Data showing various media used by respondents 
Table 5: Activity after receiving a Facebook post

\begin{tabular}{|l|l|l|}
\hline Reaction & General FB Posts & Arab Spring Related FB Posts \\
\hline Read/watch and forget & 0 & 0 \\
\hline Comment/Like & $4(6.7 \%)$ & $3(5 \%)$ \\
\hline Share it with all friends & $3(5 \%)$ & $6(10 \%)$ \\
\hline Share it with Arab Spring friends & $53(88.3 \%)$ & $44(73.3 \%)$ \\
\hline Immediately call active members to know more & Not Applicable & $7(11.7 \%)$ \\
\hline Total & 60 & 60 \\
\hline
\end{tabular}

Though some research articles speak about access and utilization of social media, no studies so far have been done on the use of Facebook by Arab Spring activists. The study was successful and brought out the role of Facebook on Arab Spring, a socio-political movement.

\section{Conclusion}

Thus, the study found that all the respondents were active Facebook users with notably high Facebook access levels and related activity. Almost all the activists were accessing Facebook on their mobile phone. In the war-torn Yemen, due to political instability and distribution / broadcast hazards, printed newspapers and television were very difficult to access. All the respondents accessed news through internet based platforms. Majority stated that FB has helped the movement along with television channels like Al-Jazeera. However, FB was considered vital in connecting the members and keeping them informed about the day-today affairs of the movement and events that were happening in Yemen.

\section{References}

AttonC (2010) Reshaping Social Movement Media for a New Millennium. Taylor \& Francis Group.3-15.

Christensen M (2013) New media geographies and the Middle East. Television \& New Media 14(4): 267-270.

CNN (2011) Wire Staff. 29 April 2011. Available in Almasryalyoum.com.

EmsL (2014) Twitter's Place in the Tussle: How Old Power Struggles Play out on a New Stage. Media, Culture and Society 36(5): 720-731.

Hassouna N (2014) New media. Alukah Culture 16: 1. Available at http://www.alukah.net/culture/0/67973

Karagiannopoulos V (2012) The Role of the Internet in Political Struggles: Some Conclusions from Iran and Egypt. Taylor \& Francis Group.

Kietzmann JH, Hermkens K, McCarthy IP and Silvestre BS (2011) Social media? Get serious! Understanding the functional building blocks of social media. Business horizons 54(3):241-251.
Kirat M (2013) New media, public sphere, and Arab Spring: Demystifying the power of social networks. Journalism and mass communication 3(4): 238-251.

Knight M (2013) Social media for journalists. Cultural studies and psychology. 288.

Lagos TG (2013) Parallel poleis: Towards a theoretical framework of the modern public sphere, civic engagement and the structural advantages of the internet to foster and maintain parallel socio-political institutions. sage journal: 76.

Markham T (2014) Social media, protest cultures and political subjectivities of the Arab Spring. Media, culture and society. 36(1): 89-104.

Marom N (2013) Activising space: The spatial politics of the 2011 protest movement in Israel. Urban Studies. 50(13): 28262841.

Odine M (2013) Role of Social Media in the Empowerment of Arab Women. Global Media Journal: 1-30.

Olorunnisola AA and Martin BL (2013) Influences of media on social movements: Problematizing hyperbolic inferences about impacts. Telematics and Informatics 30(3): 275-288.

Olorunnisola ABM (2013) Influences of Media on Social Movements: Problematizing Hyperbolic Inferences About Impacts. Telematics and Informatics: 275-288.

Osrecki A (2014) The new media and Arab Spring. Politièkamisao: Croatian Political Science Review 51(3): 101-122.

Ramesh S (2014) What Tahrir Square Has Done for Social Media. The Information Society 30: 71-80.

Ryan Y (2011). How Tunisia's revolution began: Features. Al Jazeera English. Available in Al Jazeera.com, Retrieved Feb 2016).

Sorour MK and Lal DB (2014) Energising the political movements in developing countries: The role of social media. Capital \& Class 38(3): 508-515.

Steinert-Threlkeld ZC, Mocanu D, Vespignani A and Fowler J (2015) Online social networks and offline protest. EPJ Data Science 4(1): 19. 